\title{
Refractory Oedema of Nephrotic Syndrome in a Resource Poor Setting: A Case Presentation
}

\author{
Nneka Chioma Okoronkwo ${ }^{1,2^{*}}$, Chukwuemeka Ngozi Onyearugha1,2, Ikechukwu Frank Ogbonna ${ }^{3}$ \\ ${ }^{1}$ Department of Paediatrics, Abia State University, Uturu, Nigeria \\ ${ }^{2}$ Department of Paediatrics, Abia State University Teaching Hospital, Aba, Nigeria \\ ${ }^{3}$ Department of Paediatrics, Federal Medical Centre, Umuahia, Nigeria \\ Email: *nnekaceo@rocketmail.com
}

How to cite this paper: Okoronkwo, N.C., Onyearugha, C.N. and Ogbonna, I.F. (2018) Refractory Oedema of Nephrotic Syndrome in a Resource Poor Setting: A Case Presentation. Case Reports in Clinical Medicine, 7, 37-46.

https://doi.org/10.4236/crcm.2018.71003

Received: December 5, 2017

Accepted: January 9, 2018

Published: January 12, 2018

Copyright $\odot 2018$ by authors and Scientific Research Publishing Inc. This work is licensed under the Creative Commons Attribution International License (CC BY 4.0).

http://creativecommons.org/licenses/by/4.0/

\begin{abstract}
Background: Oedema, a constant feature of childhood nephrotic syndrome can be severe, enough to cause respiratory embarrassment. It can also be refractory to diuretic monotherapy. In such cases, combination of salt poor albumin (SPA) infusion and diuretics has remained the best treatment option. However, the cost of SPA has made it practically unavailable in resource-poor settings. It becomes a therapeutic dilemma when nephrotic syndrome patients of financially-constrained caregivers present with refractory anasarca in a resource-poor settings. Case review. We present a seven-year-old boy with relapsed steroid sensitive nephrotic syndrome who presented to Abia State University Teaching Hospital Aba, in respiratory distress with anasarca and a weight of 58 kilograms. SPA could not be accessed due to financial constraints. A decision to use fresh whole blood in the place of SPA, in combination with frusemide, achieved a lifesaving diuresis and regression of the anasarca. Conclusion: Whole blood is a good alternative for the treatment of refractory oedema in children with nephrotic syndrome in resource poor settings.
\end{abstract}

\section{Keywords}

Nephrotic Syndrome, Refractory Oedema, Childhood

\section{Introduction}

Nephrotic syndrome (NS) is the commonest chronic renal disease in children worldwide [1]. It is a syndrome characterized by [2] [3].

1) Heavy proteinuria: $>50 \mathrm{mg} / \mathrm{kg} /$ day or $>40 \mathrm{mg} / \mathrm{m}^{2} / \mathrm{hr}$ or a urine protein/ creatinine ratio $>2 \mathrm{mg} / \mathrm{mg}$ 
2) Hypoalbuminaemia: serum album $<2.5 \mathrm{~g} / \mathrm{dl}$

3) Oliguria: urine output $<1 \mathrm{ml} / \mathrm{kg} / \mathrm{hr}$

4) Edema

The incidence of NS is 2 - 7 cases per 100,000 children per year, while the prevalence is 16 cases per 100,000 [2]. Aetiologically, NS is divided into the primary (idiopathic) and the secondary types. The "minimal change disease" (MCD) constitutes about $76 \%$ of the idiopathic type [2]. Although about $95 \%$ of MCD patients respond to steroids, $75 \%$ of them can relapse requiring recommencement of treatment [2].

Edema has remained a constant feature of childhood nephrotic syndrome of different aetiologies. Severe oedema of NS can be refractory, not responding to prednisolone, bed rest and diuretic monotherapy. Massive generalized oedema is common in the "minimal change disease" (MCD) type [4].

The pathogenesis of oedema in NS is explained by two different hypotheses, the "underfill" and "overfill" mechanisms [2]-[8].

In the underfill hypothesis, severe hypoalbuminaemia decreases intravascular oncotic pressure, causing circulatory volume depletion and subsequent sodium and water retention [2] [3] [4] [5] [6]. The reduction in plasma oncotic pressure also causes transudation of fluid from the intravascular to the interstitial space. The "overfill" theory states that a primary renal defect in sodium excretion leads to sodium and water retention, thereby causing hypervolemia and oedema [2] [3] [4] [5] [6].

While the "underfill" state is common in MCD, the "overfill" state favors other types of NS like focal segmental glomerulosclerosis (FSGS) and various types of nephritis [4]. In the "overfill" state, intravascular volume is normal or expanded due to inappropriately stimulated renal sodium and water retention in the face of reduced glomerular filtration rate (GFR). Generally in NS, the "underfill" state is said to be more common [4].

Other mechanisms such as vascular permeability factors, water retention and activation of channels that promote sodium retention, have also been implicated in oedema formation in NS [4]. The mechanism causing the oedema of NS of various aetiologies is critical to the management of that edematous state.

The oedema of NS, being a transudate, is pitting and can become generalized. It is also more in dependent parts of the body. The greater proportion of total body water (TBW) and interstitial fluid volume in children makes them vulnerable to accumulate more oedema fluid in NS compared to adult patients [4]. NS oedema in children can become so massive as to cause respiratory embarrassment.

There are various treatment modalities of oedema of NS. These include dietary restrictions, use of diuretics, intravenous albumin infusion $(5 \%, 20 \%$ or $25 \%)$, non-protein colloid (NPC) alternatives and angiotensin inhibition [4] [5].

Dietary restriction alone is enough for patients with mild oedema because steroid therapy will also induce natriuresis. In severe oedema, dietary restriction 
is used in combination with other treatment options. Dietary sodium intake should be restricted to less than $35 \mathrm{mg} / \mathrm{kg} /$ day [4] [5]. Fluid intake is restricted to patient's insensible losses plus previous day's urine output.

Diuretics as monotherapies in the management of oedema of nephrotic syndrome should be used with caution [2]-[8].

This is because of their potential risk for causing AK1, thrombo-embolism and electrolyte imbalance [2] [3] [4] [5] [6]. Diuretics should be used in an inpatient setting, especially in "underfill" states like minimal change nephrotic syndrome oedema. In children with gross or massive oedema, diuretics only, may not be effective in the treatment. Such children will also need in addition to the diuretics, salt-poor albumin (SPA) infusion or non-protein colloid alternatives [4] [5].

Salt-poor albumin infusion is used to increase the intravascular oncotic pressure. Twenty or $25 \%$ albumin infusion increases plasma oncotic pressure more than $5 \%$ albumin [5]. Another constraint in the use of 5\% albumin lies in the large volume required to produce significant colloid load in the face of an already existing severe oedema [5]. Infusion of SPA helps draw more fluid from the interstitial space to the intravascular compartment. The increased fluid in the intravascular space can then be flushed out using loop diuretics like furosemide. Thiazide diuretics can be added in children who are not responding well to loop diuretics [4] [5]. Bumetanide is noted for its better bioavailability over frusemide, while ethacrynic acid is used for patients with sulfonamide sensitivity [5].

Non-protein colloid substitutes like $12 \%$ dextran solution can be used to achieve diuresis at a lower cost than albumin. Angiotensin converting enzyme inhibitors exert anti-proteinuric effect which indirectly increases the plasma oncotic pressure. However, their risk of causing AKI should be weighed against this benefit [4].

The availability and use of SPA and NPC are limited by their financial costs. In resource poor settings, where the parents or guardians are financially constrained, it will be very difficult to use such options to manage anarsaca.

We, therefore present the management of a seven year old boy with relapsed steroid sensitive nephrotic syndrome and anarsaca, in a resource-poor setting.

\section{Case Presentation}

Our patient is a seven year old boy who was rushed to the children emergency room six months ago with a history of generalized body swelling of a month duration; fever, breathlessness, prostration and reduced urinary output of two weeks duration. These complaints were prior to presentation.

He has been on management for steroid sensitive nephrotic syndrome, MCD, diagnosed at the age of four years. His parents were not compliant with his medical reviews, and would rather practice self-medication whenever he fell ill. He had four relapses in the past three years and in each occasion he achieved remission following recommencement of prednisolone. He was lost to follow-up 
for more than a year before re-presenting to our hospital in a critical state.

At presentation, he was acutely ill-looking, in severe respiratory distress, febrile with axillary temperature of $37.8^{\circ} \mathrm{C}$, and could not walk. He was moderately pale, had peri-orbital fullness and generalized pitting oedema involving the entire lower limbs, abdominal and thoracic walls, sacral region, scrotum and penis (Figure 1 \& Figure 2). His weight was $58 \mathrm{~kg}$ (expected weight for his age is $22 \mathrm{~kg}$ ). He was tachypneic and tachycardic with respiratory and pulse rates of 60 breaths per minute and 120 beats per minute respectively. His blood pressure was $100 / 60 \mathrm{mmHg}$, oxygen saturation was $92 \%$ on room air. The heart was not enlarged clinically. Heart sounds were normal but distant due to the oedematous chest wall. No murmur or gallop rhythm was heard. He could not lie down

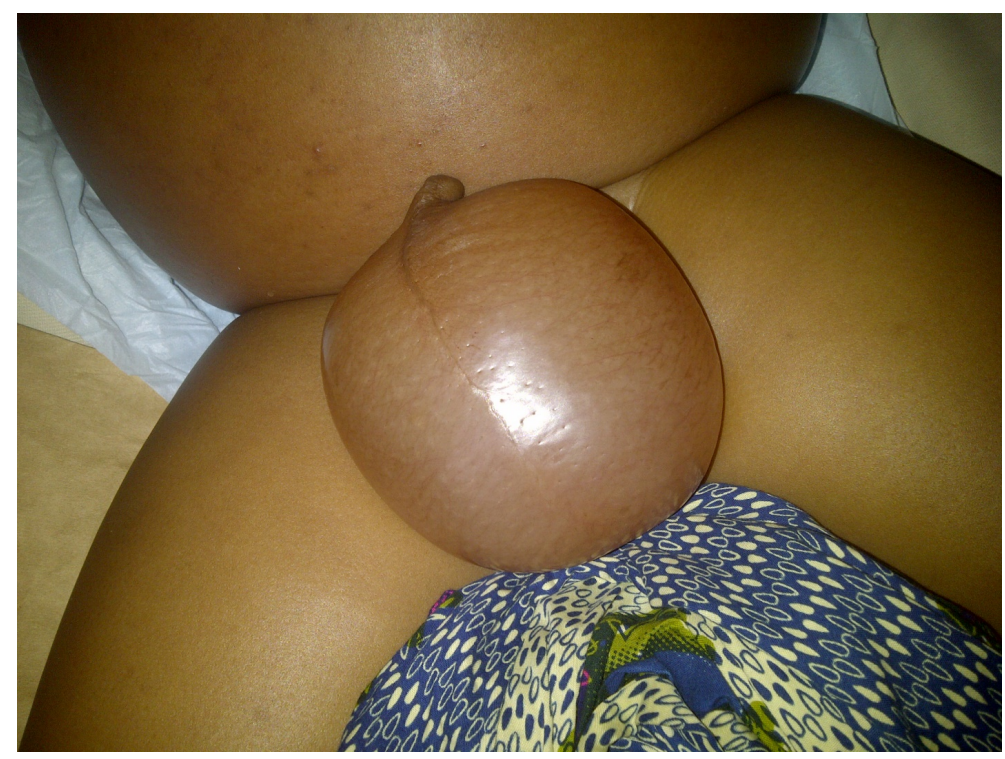

Figure 1. Scrotal oedema at presentation.

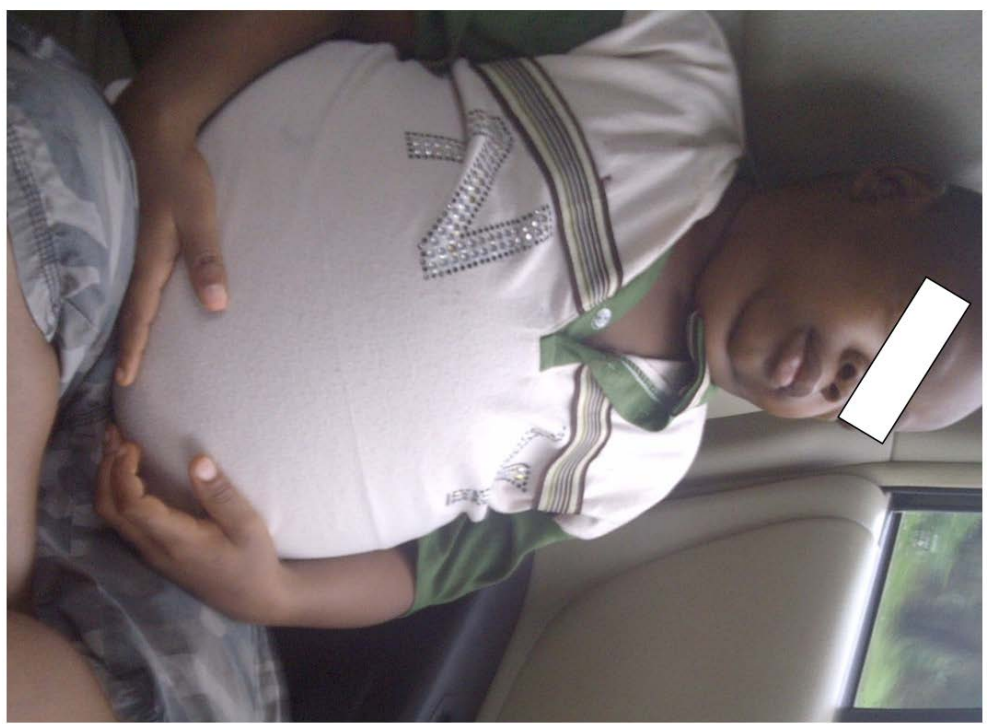

Figure 2. Patient at presentation. 
flat in bed but felt better when propped up. Both lung fields were dull to percussion with reduced air entry and crepitation posteriorly. His abdomen was markedly distended, shiny, tense and mildly tender. Ascites was demonstrable by fluid thrill and abdominal organs were difficult to palpate. Neurological examination was normal.

Laboratory values on admission were as follows: urinalysis revealed proteinuria $4+, \mathrm{pH}$ of 6 and specific gravity of 1.020. Urine microscopy showed few granular casts. Serum electrolytes were... Na $145 \mathrm{mmol} / \mathrm{L}, \mathrm{K}^{+} 5.5 \mathrm{mmol} / \mathrm{L}, \mathrm{Cl}^{-} 116$ $\mathrm{mmol} / \mathrm{L}, \quad \mathrm{HCO}_{3}^{-} 20 \mathrm{mmol} / \mathrm{L}$, creatinine $1.9 \mathrm{mg} / \mathrm{dl}$, and urea $35 \mathrm{mg} / \mathrm{dl}$. Total serum protein was $44 \mathrm{~g} / \mathrm{L}$, albumin was $15 \mathrm{~g} / \mathrm{L}$, and serum cholesterol was 360 $\mathrm{mg} / \mathrm{dl}$. An early morning protein creatinine ratio was $6 \mathrm{mg} / \mathrm{mg}$. A complete blood count revealed Hb-8 g/dl, WBC-14,000 $\times 10^{9} / \mathrm{mm}^{3}$ (N-70\% L-30\%), and platelet of $200,000 / \mathrm{mm}^{3}$. Bladder catheterization yielded about $5 \mathrm{mls}$ of concentrated urine which was sent for microscopy culture and sensitivity. The result showed significant growth of Escherichia coli bacteria. Malaria parasite and retroviral screen tests were negative. Abdominal ultrasound and chest radiograph were not done due to financial constraints.

A diagnosis of relapsed steroid sensitive nephrotic syndrome with anarsaca and co-existing urinary tract infection was made. He was admitted and commenced on intranasal oxygen. The following medications were also ordered: intravenous (IV) cefuroxime $70 \mathrm{mg} / \mathrm{kg} /$ day in two divided doses, IV Lasix $4 \mathrm{mg} /$ $\mathrm{kg} /$ day in four divided doses and oral prednisolone $60 \mathrm{mg}$ every morning, taken with meals. He was nursed in cardiac position to help relieve the respiratory distress. A fluid input/output chart, with 6 hourly BP monitoring was instituted. Fluid intake was restricted to previous day's urine output plus $300 \mathrm{ml} / \mathrm{m}^{2}$. "No added salt to diet" was also instituted.

After 24 hours of IV furosemide (Figure 3), there was no improvement in the patient's oedematous state. Rather, there were early symptoms of hypovolaemia. Decision was to give the patient a salt poor albumin or dextran solution infusion. However, there was none in the hospital and patient could not afford one from outside the hospital. We were at a dilemma on what to use, as we could no longer continue diuretic monotherapy.

A decision was made to use fresh whole blood as an alternative. This was because patient was both moderately pale, hypovolaemic and also had hypoalbuminaemia. Diuretics was discontinued until the first blood transfusion. He received a total of three aliquots of blood transfusion, each given every other day within the first six days of admission.

Each aliquot of blood was $15 \mathrm{mls} / \mathrm{kg}$ over 6 hours on day 2, day 4, and day 6 of admission. He also received $60 \mathrm{mg}$ of IV Lasix at 2 hours into transfusion, and then another dose immediately after transfusion. This was done for each of the aliquots of the blood transfusions. He was also maintained on low dose furosemide $0.5 \mathrm{mg} / \mathrm{kg}$ per dose 12 hourly until a day after the $3^{\text {rd }}$ aliquot of blood transfusion. His estimated urinary output was $<0.5 \mathrm{ml} / \mathrm{kg} / \mathrm{hr}$ on admission. 


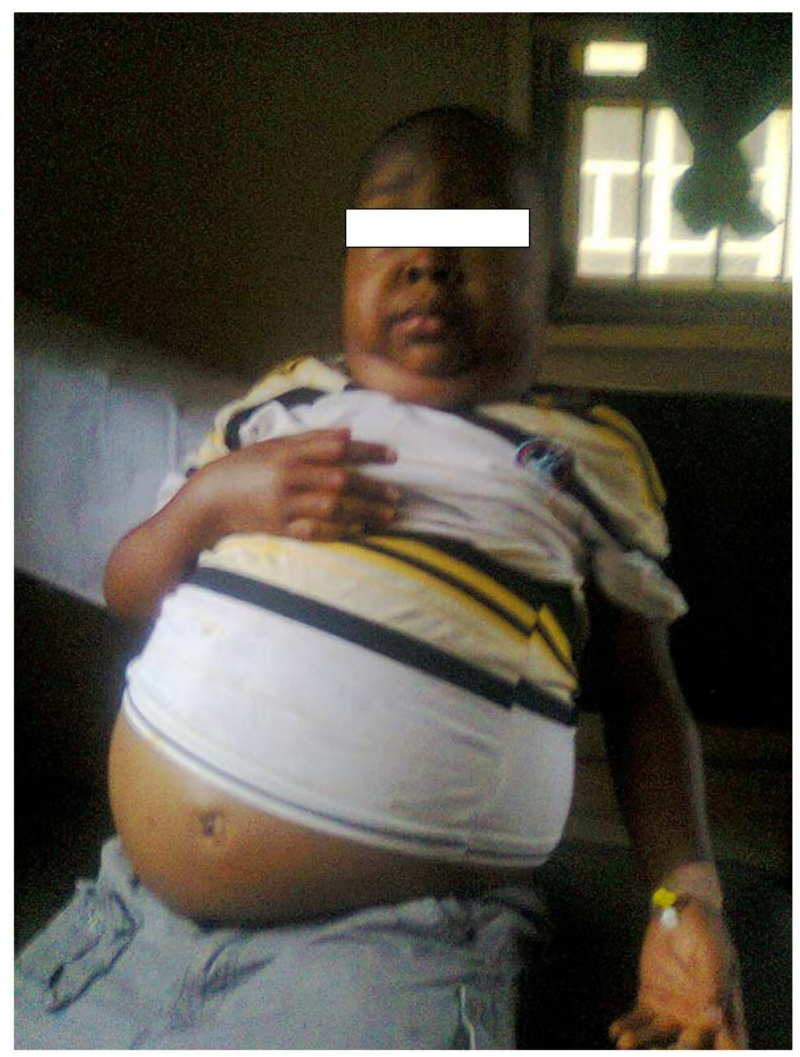

Figure 3. Patient some hours after admission.

However this started improving after the first aliquot of blood transfusion. The peripheral oedema also began to regress. His scrotal oedema remained the same until after the $3^{\text {rd }}$ aliquot of blood transfusion. On the $5^{\text {th }}$ day of admission, he was no longer dyspnoeic and could lie down using one pillow. At this point his legs were elevated on a pillow while the scrotum was supported/elevated using a rolled piece of soft cotton cloth. Gradually, he lost all his oedema fluid within ten days of admission (Figure 4).

On discharge, after 2 weeks of admission, he had already entered remission. Serum protein was now $62 \mathrm{~g} / \mathrm{l}$, while albumin was $26 \mathrm{~g} / \mathrm{l}$. His $\mathrm{Hb}$ was now 12 $\mathrm{g} / \mathrm{dl}$, his weight had dropped to $38 \mathrm{~kg}$, and the serum electrolyte, urea and creatinine had all normalized. His parents were counseled on the need to keep up medical appointments. Also on discharge, his prednisolone was changed to 60 mg alternate day for one month. Thereafter, the dose was gradually reduced on weekly basis. He is presently maintained on $5 \mathrm{mg}$ of presdnisolone alternate day, in combination with alternate day levamisole $(75 \mathrm{mg})$. He has come for follow-up $5 \times$ since then. He is still stable and in remission 6 months after discharge.

\section{Discussion}

The degree of oedema in our patient was severe [2] (weight gain $>10 \%$ ) and refractory. It did not respond to initial maximum doses of IV furosemide. We did not add spironolactone then because the serum $\mathrm{k}^{+}$was already $5.5 \mathrm{mmol} / \mathrm{L}$. 


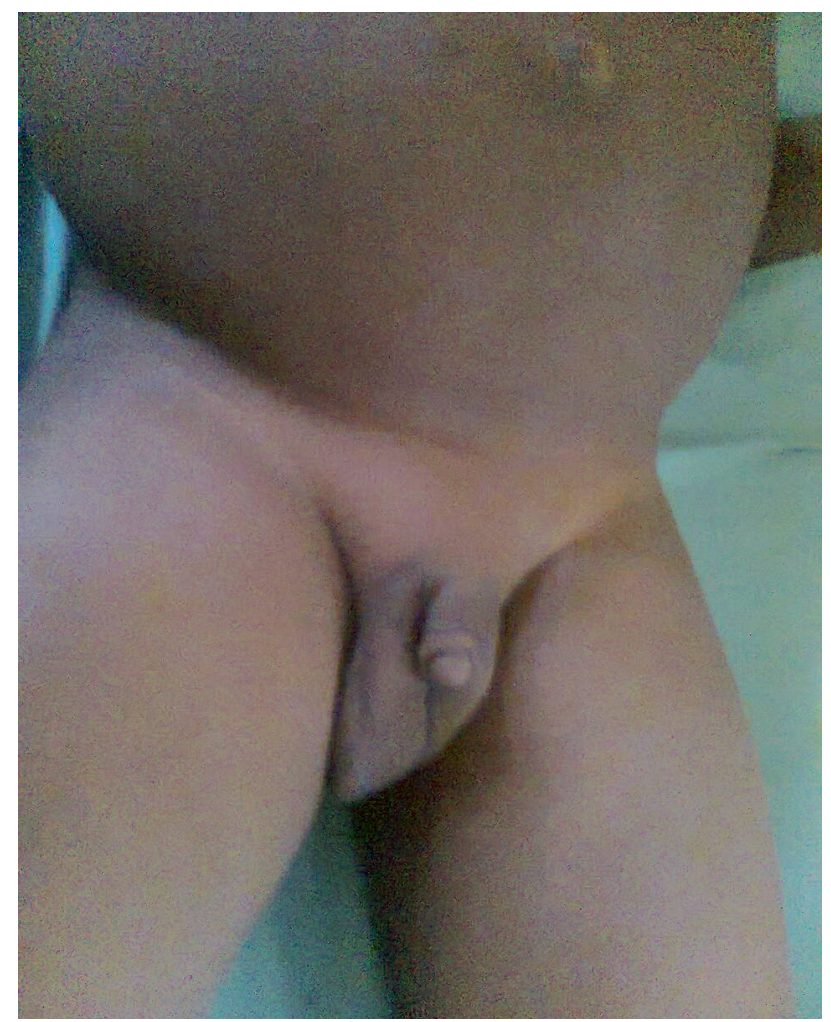

Figure 4. Ten days after admission showing marked resolution of body oedema, the scrotum inclusive.

Pasini et al. [2] suggested a co-administration of a thiazide diuretic in such cases.

Symptoms of hypovolaemia in the index patient contraindicated further use of diuretics monotherapy in this case. Infusion of $20 \%$ or $25 \%$ albumin $(0.5-1 \mathrm{~g} / \mathrm{kg}$ over 3 - 4 hrs) with one or two boluses of IV furosemide $(1 \mathrm{mg} / \mathrm{kg})$ given during or at the end of the infusion [2] [4] should have been the ideal treatment option for us. However, albumin infusion was not available in our hospital, and our patient could not afford it from outside the hospital. Albumin infusions and NPC are expensive and in low supplies [4]. Unavailability of PSA and Dextran solution in our hospital, and financial constraints on the side of the patient, made it impossible for us to use these in the management of the gross oedema.

Fresh whole blood transfusion was our cheapest most available colloid option for this patient. He was moderately pale with hypovolaemia and hypoproteinaemia. Fresh whole blood could meet these needs at that point in time. Specifically, for the intractable oedema, it is assumed that the serum proteins in the blood will increase the intravascular oncotic pressure, thereby causing fluid to be drawn into the vascular compartment from the interstitial space. As intravascular volume increased, intravenous furosemide is given as a bolus at 2 hours and at the end of the transfusion, to flush out fluid through the kidneys. The whole blood transfusion is also believed to improve renal perfusion and subsequently renal function and diuresis.

Colloid (e.g. albumin, blood) infusions raise plasma oncotic pressure, facili- 
tates interstitial fluid reabsorption and supports plasma volume. Addition of diuretics enhances fluid removal [2] [4] [7].

Albumin infusion, together with diuretics, induces profound diuresis compared to use of diuretics as monotherapy [9] [10] [11] [12]. Although fresh whole blood does not have the same quantity of proteins as in concentrated albumin infusions, the pathophysiology of oedema resolution is the same.

In patients without anaemia and in the absence of PSA and non-protein colloid alternatives, in resource poor settings, pooled serum transfusion (without red blood cells) is the best option.

Expansion of plasma volume (by either PSA, NPC, whole blood or pooled serum) suppresses vasopressin release induced by hypovolaemia, thereby increasing water diuresis [4].

Fifteen $\mathrm{mls} / \mathrm{kg}$ of blood was used for each aliquot of blood transfusion instead of the usual $20 \mathrm{mls} / \mathrm{kg}$ for whole blood transfusions. By this reduction, we were playing on the side of caution in preventing cardiovascular overload in the face of reduced urinary output. Achieving plasma expansion with colloids should be done with caution in patients with oliguria, so as to avoid cardiovascular overload with hypertension and pulmonary oedema [5].

Three aliquots of blood transfusions were given before achieving significant resolution of the severe oedema. This is because the effect of each aliquot of colloid transfusion/infusion is transient, making patients with severe oedema to require repeat transfusions/infusions [2].

The loss of oedema fluid in our patient was gradual. The scrotal oedema was the last to resolve. Natriuresis initiated by colloid transfusions should be sustained with low dose ( $1-3 \mathrm{mg} / \mathrm{kg} / \mathrm{day})$ frusemide, until all peripherial oedema resolves [2].

Pasini et al. [2] suggested a gradual loss of oedema fluid over one week for cases of moderate oedema. Aggressive use of high dose diuretics to achieve fast resolution of oedema usually ends with intravascular hypovolaemia or its exacerbation [2] [3] [4] [5] [6].

The intractable scrotal oedema needed additional support and elevation with rolled piece of cloth. Swollen scrotum is usually elevated with pillows to enhance removal of fluid by gravity [12]. This enhances gravitational drainage of oedema fluid back to the lymphatic/venous channels [7]. Intermittent cold compresses were applied to the oedematous scrotum initially when patient was complaining of scrotal pain.

\section{Conclusion}

Combination of albumin infusion and diuretics remains a long standing standard therapy for severe oedema in NS. However, both intravenous salt poor albumin and NPC solutions are not easily available in resource poor settings because of their costs. When financial constraints preclude their use in NS patients with severe oedema, whole blood or pooled serum transfusion becomes an effective colloid alternative. 


\section{Consent}

A written informed consent was obtained from the patient's father for this publication and the pictures. A copy of it is available for review by the editor-in-chief of this journal.

\section{Author's Contribution}

Dr Okoronkwo designed and wrote the manuscript, while Dr Onyearugha and Dr Ogbonna edited it.

\section{Conflict of Interest}

There is no conflict of interest.

\section{Funding}

None.

\section{References}

[1] Okoronkwo, N.C., Ibeneme, C.A., Nwala, G.C. and Ezuruike, E. (2014) Nephrotic Syndrome as Seen at The Department of Paeditrics of The Federal Medical Centre, Umuahia, Nigeria. African Journal of Paediatric Nephrology, 1, 62-66.

[2] Pasini, A., Benetti, E., Conti, G., Ghio, L., Lepore, M., Massella, L., et al. (2017) The Italian Society for Paediatric Nephrology Consensus Document on the Management of Nephrotic Syndrome in Children: Part 1-Diagnosis and Treatment of the First Episode and the First Relapse. Italian Journal of Pediatrics, 43, 41. https://doi.org/10.1186/s13052-017-0356-x

[3] Bhimma, R. (2014) Steroid Sensitive Nephrotic Syndrome in Children. Journal of Nephrology \& Therapeutics, S11, 003. https://doi.org/10.4172/2161-0959.S11-003

[4] Ellis, D. (2016) Pathophysiology, Evaluation, and Management of Edema in Childhood Nephrotic Syndrome. Frontiers in Pediatrics, 3, 111. https://doi.org/10.3389/fped.2015.00111

[5] Cadnapaphornchai, M.A., Tkachenko, O., Shchekochikhin, D. and Schrier, R.W. (2014) The Nephrotic Syndrome: Pathogenesis and Treatment of Edema Formation and Secondary Complications. Pediatric Nephrology, 29, 1159-1167. https://doi.org/10.1007/s00467-013-2567-8

[6] Kapur, G., Valentini, R.P., Imam, A.A. and Mattoo, T.K. (2009) Treatment of Severe Edema in Children with Nephrotic Syndrome with Diuretics Alone-A Prospective Study. Clinical Journal of the American Society of Nephrology, 4, 907-913. https://doi.org/10.2215/CJN.04390808

[7] O’Brien, J.G., Chennubhotla, S.A. and Chennubhotla, R.V. (2005) Treatment of Edema. American Family Physician, 71, 2111-2117.

[8] Hisano, S., Hahn, S., Kuemmerle, N.B., Chan, J.C.M. and DeSanto, N.G. (1997) Edema in Childhood. Kidney International, 51, S100-S104.

[9] Fliser, D., Zurbruggen, I., Mutschler, E., Bischoff, I., Nussberger, J., Frank, E., et al. (1999) Coadministration of Albumin and Frusemide in Patients with Nephrotic Syndrome. Kidney International, 55, 629. https://doi.org/10.1046/j.1523-1755.1999.00298.x 
[10] Hodson, E. (2003) Management of Idiopathic Nephrotic Syndrome in Children. Pediatric Drugs, 5, 335-349. https://doi.org/10.2165/00128072-200305050-00006

[11] Haws, R.M. and Baum, M. (1993) Efficacy of Albumin and Diuretic Therapy in Children with Nephrotic Syndrome. Pediatrics, 91, 1142-1146.

[12] Behrman, R.E., Kliegman, R.M. and Jenson, H.B. (Eds.) (2008) Nephrotic Syndrome in Nelson Textbook of Paediatrics. 18th Edition, Saunders, Philadelphia, PA, 2190-2195. 